\title{
RESEARCH
}

Open Access

\section{Development of digital diagnostic templates by cluster analysis based on 2249 lateral cephalograms of Chinese Han population}

Hong Su ${ }^{1,2,3 \dagger}$, Wenhsuan Lu, ${ }^{1,3 \dagger}$, Jingjing Deng ${ }^{3,4}$, Gui Chen ${ }^{1,3}$, Ruoping Jiang ${ }^{1}$, Yan Wei ${ }^{3,4^{*}}$, Xiaoyun Zhang ${ }^{1,3}$, Tianmin $\mathrm{Xu}^{1,3^{*}}$ and Bing $\operatorname{Han}^{1,3^{*}}$ (D)

\begin{abstract}
Background: To establish the digital diagnostic templates by cluster analysis based on a set of cephalometric films and evaluate the outcome of the different treatment methods in the patients affiliated to the same cephalometric morphology template (CMT). These templates could be used for the automatic diagnosis of dentofacial deformities and prediction of treatment outcomes in the future.

Methods: In this study, we assessed the coordinates of 60 different landmarks on the cephalograms of 2249 patients ( $14.35 \pm 4.99$ years, range from 7 to 62$)$ with dentofacial deformities. The cephalometric data were subjected to dentist for clustering without a priori pattern definitions to generate biologically informative CMTs. Three templates were selected to evaluate the treatment outcome of patients affiliated to the same CMT.

Results: The cluster analysis yielded 21 distinct groups. The total discriminant accuracy was $89.1 \%$, while the crossvalidation accuracy was $85.0 \%$, showing that the clusters were robust. All CMTs were automatically created and drawn using a computer, based on the average coordinates of each cluster. Individuals affiliated to the same CMT showed similar dentofacial features. We also evaluated differences in the outcomes of patients affiliated to the same CMT.
\end{abstract}

\footnotetext{
* Correspondence: kqweiyan@bjmu.edu.cn; tmxuortho@163.com;

kqbinghan@bjmu.edu.cn

${ }^{\dagger}$ Hong Su and Wenhsuan Lu contributed equally to this work.

${ }^{3}$ National Center of Stomatology \& National Clinical Research Center for Oral Diseases \& National Engineering Research Center of Oral Biomaterials and Digital Medical Devices \& Research Center of Engineering and Technology for Computerized Dentistry Ministry of Health \& NMPA Key Laboratory for Dental Materials, 22 Zhongguancun South Avenue, Haidian District, Beijing 100081, People's Republic of China

'Department of Orthodontics, Cranial-Facial Growth and Development Center, Peking University School and Hospital of Stomatology, 22 Zhongguancun South Avenue, Haidian District, Beijing 100081, People's Republic of China

Full list of author information is available at the end of the article
}

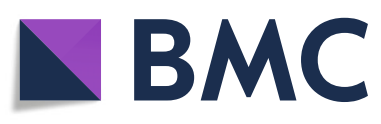

(c) The Author(s). 2022 Open Access This article is licensed under a Creative Commons Attribution 4.0 International License, which permits use, sharing, adaptation, distribution and reproduction in any medium or format, as long as you give appropriate credit to the original author(s) and the source, provide a link to the Creative Commons licence, and indicate if changes were made. The images or other third party material in this article are included in the article's Creative Commons licence, unless indicated otherwise in a credit line to the material. If material is not included in the article's Creative Commons licence and your intended use is not permitted by statutory regulation or exceeds the permitted use, you will need to obtain permission directly from the copyright holder. To view a copy of this licence, visit http://creativecommons.org/licenses/by/4.0/. The Creative Commons Public Domain Dedication waiver (http://creativecommons.org/publicdomain/zero/1.0/) applies to the data made available in this article, unless otherwise stated in a credit line to the data. 
Conclusions: Our results demonstrated the utility of clustering methods for grouping dentofacial deformities with similar dentofacial features. Clustering methods can be used to evaluate the differences in the outcomes of patients affiliated to the same CMT, which has good clinical application value.

Keywords: Dentofacial deformity, Cluster analysis, Discriminant analysis, Cephalometric morphology template, Diagnosis

\section{Background}

Dentofacial deformities are a heterogenous group of disorders that affect numerous people worldwide. Orthodontists and orthognathic surgeons require a comprehensive understanding of the cranio-dento-facial tissues of each patient to arrive at an accurate diagnosis and devise appropriate treatment plans. Since the X-ray technique [1] was introduced into the orthodontic field, cephalograms have become one of the most important tools to understand dentofacial structures, predict growth, make diagnoses and evaluate treatments. Before computerization, manual cephalometric analysis was mainly used to assist orthodontists in analyzing the mechanisms underlying malocclusions. The existing analytic methods of cephalometry are mostly different combinations of line distances and angle measurements [24], which are used to diagnose deformities on the basis of comparisons with reference values. However, even more data of cephalometrics are unable to represent the overall craniofacial morphology very well and directly deduce the overall dentofacial morphology from different combinations of partial comparisons. In addition, the use of routine cephalometrics is time-consuming, the operator needs to consider all the possible crossover interpretation of cephalometric value. To overcome this problem, graphic template analysis based on average dentofacial morphologies was developed to enable comprehensive morphological diagnoses and give the operator the opportunity to be more efficient with lessconsuming time and less effort.

Manual templates formed from an expanding cephalogram database of growing individuals have been used to evaluate the overall dentofacial morphology of patients $[5,6]$ and even to predict growth [7]. Likewise, cephalograms of patients with malocclusions have been agematched with templates prepared using cephalograms of individuals with normal occlusion from birth to 18 years of age, so as to enable diagnoses and explore the mechanisms of malocclusion [8]. These studies showed that template analysis makes it much easier to judge the contour features of different growth patterns and is more intuitive than traditional cephalometric measurements. Therefore, we consider that digital, automated template matching might be the key to realize fully automatic, computed diagnoses of dentofacial deformities and predict treatment outcomes.
The first step in establishing applicable digital templates is to develop reasonable sample classifications. Current classifications of malocclusion are mostly based on dental relationships such as Angle's classification or on certain skeletal characteristics such as the ANB angle or $\mathrm{MP} / \mathrm{SN}$ angle [3, 4]. Although a single value can help to judge a certain dentofacial feature, it cannot accurately represent the overall dentofacial morphology, since different orthodontists prefer different cephalometric indexes, the overall patient evaluation can vary. In recent years, a growing number of authors have started using mathematical methods such as geometry, statistics and computer analysis to assess the overall dentofacial morphology and explain similarities between samples [9-18]. One such method, cluster analysis, can group individuals in a given sample according to a certain feature and therefore provides a detailed description of the population while taking into account its intrinsic heterogeneity. This type of analysis has been garnering increasing attention in the dental field for classification purposes and epidemiological studies [19-23]. They have demonstrated that clustering the patterns of dentofacial deformities is beneficial for epidemiological diagnosis, treatment evaluation, and outcome prediction. Some authors have tried to cluster certain types of malocclusions into subclasses with typical dentofacial characteristics [20]. In addition to classification purposes and epidemiological studies, cluster analysis has also been used for more practical aspects of orthodontics [18]. Some authors have used it to identify anatomic characteristics that may influence bonding in the straight-wire technique. However, because most of these studies were partial and based on relatively small samples, their results pertain to only specific categories of certain types of malocclusions, and are limited in their ability to classify all types of dentofacial deformities.

This study aimed to cluster the cranio-dento-facial deformities of 2249 patients without a priori pattern definitions into biologically informative cephalometric morphology templates (CMTs) based on cephalogram coordinates and to explore the utility of the resultant templates for diagnosis and treatment evaluation. In this way, we hoped to help provide a novel method to evaluate and predict treatment outcomes. 


\section{Materials and methods}

\section{Sample recruitment and data collection}

The sample used in this study was recruited through a database comprising $>11,000$ patients who had malocclusion and had finished orthodontic treatment between 1997 and 2005 at the Peking University School and Hospital of Stomatology (PKUSS; Beijing, China). The study protocol was approved by the ethics committee of Peking University School of Stomatology (PKUSSIRB-201626016), got approval to dispense with informed consent, and adhered to the tenets of the Declaration of Helsinki. The study has been registered with the Chinese Clinical Trial Registration (ChiCTR1800017694).

The inclusion criteria were as follows: Chinese Han population; no hereditary diseases; undamaged lateral cephalograms taken before and after the treatments were available; and all cephalograms were obtained using Orthopantomograph OC100 (Instrumentarium Dental, Nahkelantie, Finland.) Data on several covariates were collected. The clinical records were used to gather data on sex, age at first visit, birth year, Angle's classification, treatment methods, treatment design, and treatment duration. A total of 2249 patients in the database who met the inclusion criteria formed the study cohort. Among the 2249 study patients, there were 758 males (33.7\%) and 1491 females (66.3\%), with a mean age of $14.35 \pm 4.99$ years at the beginning of treatment (range from 7 to 62). Angle class I malocclusions were the most common (945 patients; $42.0 \%)$, followed by class II (872 patients; $38.8 \%$ ) and class III malocclusions (432 patients; $19.2 \%)$.

\section{Landmark identification}

Lateral cephalograms were provided by the radiology department of PKUSS. To control magnification, all head films were taken with the same cephalostat. All traditional films were calibrated for length scales and then scanned into digital image files (.tiff). The magnification produced from the projection and scanning procedures was calculated and corrected by the computer.

Cephalometric landmarks were located by three residents who were blinded to the goals of our study and professionally trained in the definition of each point and

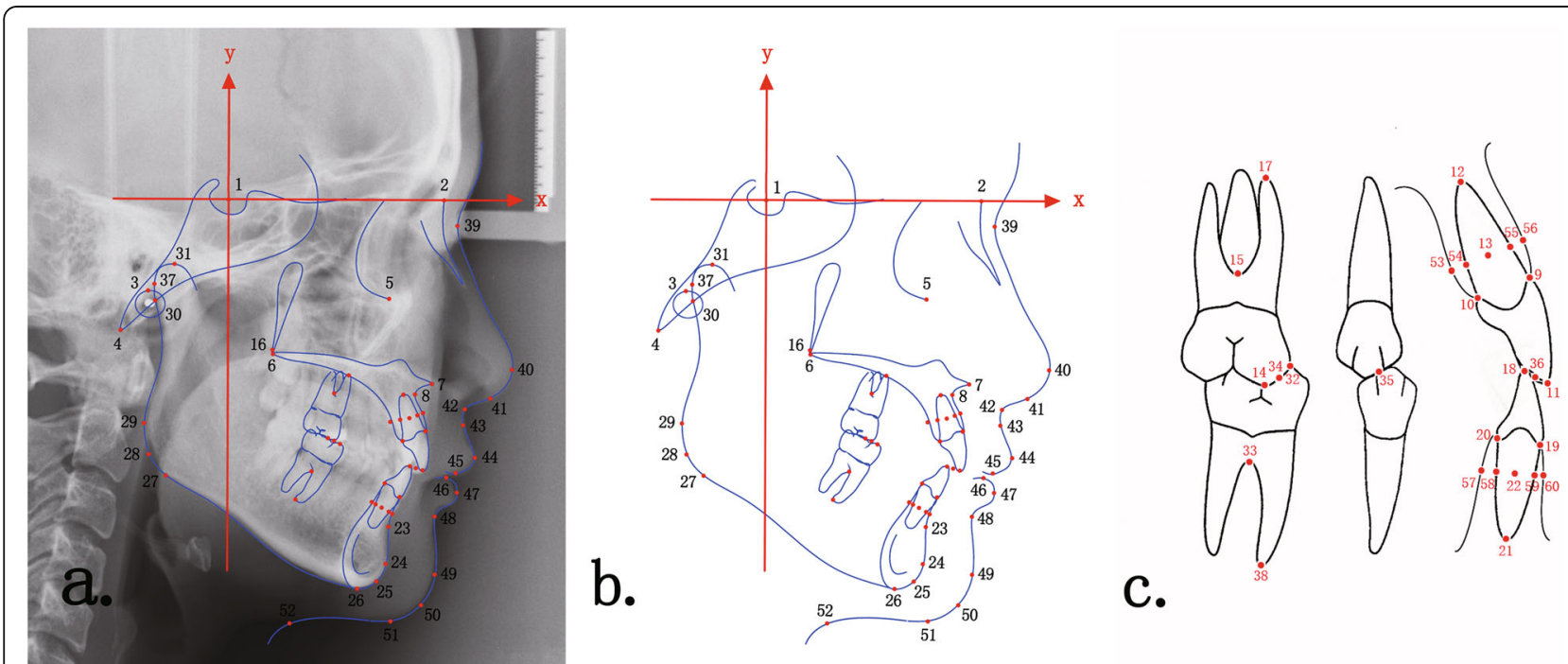

Fig. 1 Cephalometric landmarks (schematic) of craniofacial hard and soft tissues. 1: sella (S); 2: nasion (N); 3: porion (P); 4: basion (Ba); 5: orbitale (Or); 6: posterior nasal spine (PNS); 7: anterior nasal spine (ANS); 8: subspinale (A); 9: superior prosthion (SPr); 10: palatal superior prosthion (Spr(p)); 11: edge of upper incisor (UIE); 12: apex of upper incisor (UIA); 13: resistance of upper incisor (UIR); 14: mesial buccal cusp of upper first molar (UMC); 15: resistance of upper first molar (UMR); 16: pterygomaxillary fissure (Ptm); 17: mesial buccal apex of upper first molar (UMA); 18: edge of lower incisor (LIE); 19: infradentale (Id); 20: lingual infradentale (Id(I)); 21: apex of lower incisor (LIA); 22: resistance of lower incisor (LIR); 23: supramental (B); 24: pogonion (Pg); 25: gnathion (Gn); 26: menton (Me); 27: tangent gonion (Tgo); 28: gonion (Go); 29: posterior gonion (Gop); 30: articulare (Ar); 31: condylion (Co); 32: mesial cusp of lower first molar (LMC); 33: resistance of lower first molar (LMR); 34: midpoint of UMC and LMC (Interdental-M); 35: midpoint of upper and lower second bicuspids (Interdental-B); 36: midpoint of UIE and LIE (Interdental-I); 37: posterior condylion (Cop); 38: mesial apex of lower first molar (LMA); 39: nasion of soft tissue (Ns); 40: pronasale (Prn); 41: columella (Cm); 42: subnasale (Sn); 43: subspinale of soft tissue (As); 44: upper lip (UL); 45: stomion superius (Stoms); 46: stomion inferius (Stomi); 47: lower lip (LL); 48: supramental of soft tissue (Bs); 49: pogonion of soft tissue (Pos); 50: gnathion of soft tissue (Gns); 51: menton of soft tissue (Mes); 52: cervical point (C); 53: posterior-resistance-on-bone of upper incisor (URP-p); 54: posterior-resistance-on-root of upper incisor (URP); 55: anterior-resistance-on-root of upper incisor (URA); 56: anterior-resistance-on-bone of upper incisor (URA-a); 57: posterior-resistance-on-bone of lower incisor (LRP-p); 58: posterior-resistance-on-root of lower incisor (LRP); 59: anterior-resistance-on-root of lower incisor (LRA); 60: anterior-resistance-on-bone of lower incisor (LRA-a) 
the method of calibrating points by the rules of standardized cephalometrics each orthodontic resident had to master. We learned the method from Baumrind and Frantz's study and obtain the personalized definitions of each landmark positions [24]. Outliers, if present, were mostly caused by inadvertent clicking on the screen, could be automatically detected with CIS (Cephalometric Information System, Peking University, Beijing, China) and were checked by the same individual. Regarding the calibration, after the residents located the cephalometric landmarks, we obtained three points of a landmark. Among the three points, if the maximum distance between two points was greater than two times the minimum distance between two points, the landmark was recalibrated. The average of three landmarks was used for subsequent calculations. In all, 46 hardtissue landmarks and 14 soft-tissue landmarks were located. All the cephalometric landmarks have been shown and explained in a schematic plot (Fig. 1).

\section{Measurement and output}

A commonly used coordinate system was employed in this study. We set the sella point (S) as the origin and the anterior cranial base plane ( $\mathrm{SN}$ ) as the $\mathrm{x}$-axis to establish a Cartesian coordinate system (Fig. 1). All the coordinates of each located landmark were outputted to form a coordinate database.

Although the primary objective of the present study was to form a digital template series, we also automatically calculated and analyzed 135 angular and linear measurements based on the coordinates by means of CIS. All measurements were listed in Table 1. The measurement values were not used as variable ranges in the cluster analysis, but were used to describe features that helped clinicians understand and apply the diagnostic templates.

\section{Statistical analysis}

Data were analyzed using SPSS version 16.0 (SPSS, Chicago, IL, USA). After clustering, the same coordinates were used as variables to perform discriminant analysis of all the clustering samples in order to obtain the discriminant equation. The derived discriminant equation should ensure the minimum error rate when the classification of a new sample is to be judged. The general form of the linear discriminant equation is as follows:

$$
Y=a 1 \times 1+a 2 \times 2+a 3 \times 3+\cdots \cdots+a n x n,
$$

where $Y$ is the discriminant value, corresponding to CMTs classify. Variables reflecting characteristics of the sample are represented as $\times 1, \times 2, \times 3 \ldots \times n$, corresponding to cephalometric measurements, and coefficients of the variables are represented as $a 1, a 2, a 3$ ... an.

After the discriminant equations were obtained, the coordinates of the original sample were substituted into the equations to calculate the overall accuracy of the discrimination. In addition, coordinates of different samples were also tested in a cross-validation analysis to verify the cross-discriminant accuracy.

The average coordinates of the samples corresponding to a particular category, as determined by the cluster analysis, reflected the mean morphology of that category. We selected some samples from certain subdivisions

Table 1 All the cephalometric measurements

\begin{tabular}{|c|c|c|c|}
\hline SNA & SN/OP2 & $\mathrm{A}-\mathrm{NPg}$ & Ns-Pos \\
\hline SNB & FH/OP1 & U1/NA & Ns-Sn \\
\hline ANB & FH/OP2 & UIE-NA & $\mathrm{NLA}(\mathrm{Cm}-\mathrm{Sn}-\mathrm{UL})$ \\
\hline SNPg & OP1/MP & U1/PP & Ns-Mes \\
\hline NSBa & $\mathrm{OP} 2 / \mathrm{MP}$ & $\mathrm{U} 1 / \mathrm{FH}$ & Stoms-Stomi \\
\hline NSAr & $\mathrm{OP} 2 / \mathrm{PP}$ & ANPr & Ns-Sn \\
\hline $\mathrm{FH} / \mathrm{NA}$ & OP1/PP & UIE-AP & Sn-Stoms \\
\hline $\mathrm{SN} / \mathrm{FH}$ & OPu/PP & UIE-PP & Sn-Mes \\
\hline S-N & OPI/MP & UMC-PP & Stomi-Bs \\
\hline S-Ba & L1/OP1 & U1/SN & Stomi-Mes \\
\hline Ba-N & $\mathrm{LI} / \mathrm{OPL}$ & $\mathrm{L} 1 / \mathrm{NB}$ & Stoms-UIE \\
\hline A-NFH & LI/OP2 & L1/MP & UIR-UMR \\
\hline Ptm-S(FH) & UI/OPu & $\mathrm{LI} / \mathrm{FH}$ & UIR-UMR(PP) \\
\hline PNS-ANS(FH) & UI/OP1 & $\mathrm{CL} / \mathrm{MP}$ & UIE-UMC \\
\hline PNS-A(FH) & $\mathrm{UI} / \mathrm{OP} 2$ & LIE-AP & UIA-UMA \\
\hline Ptm-A(FH) & LM/OPL & LIE-MP & UIA-UMA(PP) \\
\hline $\mathrm{FH} / \mathrm{NB}$ & LM/OP1 & LIE-NB & LIR-LMR \\
\hline NGoGn & LM/OP2 & LMC-MP & LIR-LMR(MP) \\
\hline SGoN & UM/OP1 & U1/L1 & LIE-LMC \\
\hline $\mathrm{MP} / \mathrm{SN}$ & UM/OP2 & UM/LM & LIA-LMA \\
\hline $\mathrm{MP} / \mathrm{FH}$ & NsPos/FH & overjet & LIA-LMA(MP) \\
\hline NSGn & S-Ns-Sn & overbite & UM/PP \\
\hline SArGo & S-Ns-Bs & UMC-LMC(OP1) & LM/PP \\
\hline $\mathrm{B}-\mathrm{NFH}$ & Sn-Ns-Bs & UMC-LMC(OP2) & Ptm/UMC(FH) \\
\hline$S L$ & S-Ns-Pos & SN/OP1 & \\
\hline SE & AsUL_BsLL & Co-Gn & Prn-H \\
\hline $\mathrm{Co}-\mathrm{S}(\mathrm{FH})$ & AsUL-FH & Go-Gn & $\mathrm{Sn}-\mathrm{H}$ \\
\hline $\mathrm{N}-\mathrm{Me}$ & BsLL-FH & $\mathrm{Pg}-\mathrm{NB}$ & Bs-H \\
\hline S-Go & PosBs-FH & ANPg & $\mathrm{LL}-\mathrm{H}$ \\
\hline S-Go/N-Me & Ns-Prn-Pos & NA/PA & UL-EP \\
\hline MP/ArGoP & Z angle & MP/PP & LL-EP \\
\hline Co-Pg(MP) & $\mathrm{H}$ angle & Wits & UL-SnPos \\
\hline ArGoGn & LL-Bs-Pos & $A-B(F H)$ & LL-SnPos \\
\hline Co-B & Sn-Gns-C & Co-Pg & Prn-SnFH \\
\hline
\end{tabular}




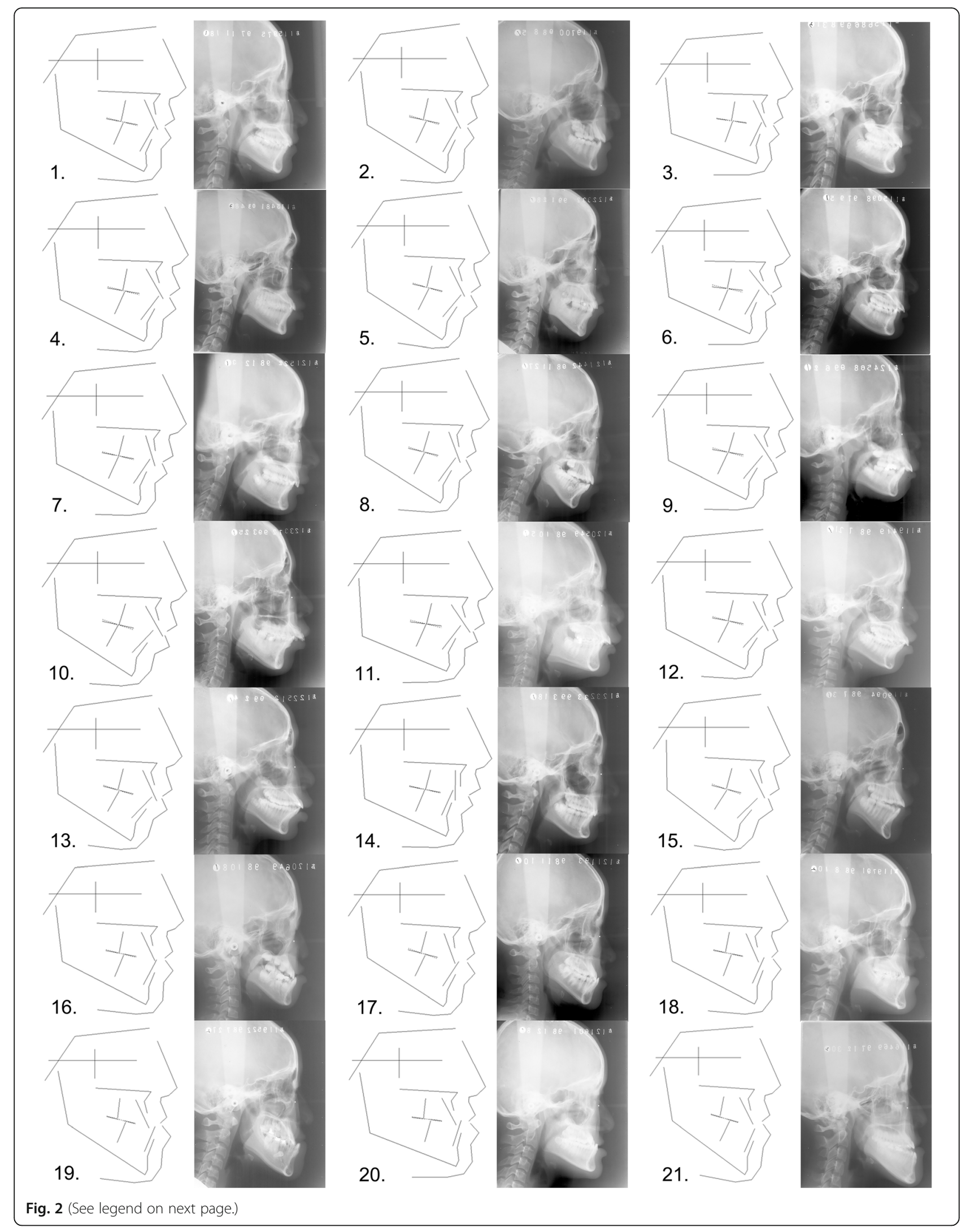


(See figure on previous page.)

Fig. 2 All the CMTs formed in this study and the corresponding typical cephalograms are showed and described referring to conventional cephalometric measurements. 1: skeletal I, mean angle, straight profile; 2: skeletal I, high angle, straight profile; 3: skeletal I, low angle, straight profile; 4: skeletal I, mean angle, bimaxillary protrusion; 5: skeletal I, high angle, bimaxillary protrusion; 6: skeletal I, deep overjet; 7: skeletal II, mean angle, retruded mandible; 8: skeletal II, high angle, retruded mandible; 9: skeletal II, mean angle, deep overjet; 10: skeletal II, high angle, deep overjet; 11: skeletal II, low angle, deep overjet; 12: skeletal II, mean angle, bimaxillary protrusion; 13: skeletal II, high angle, bimaxillary protrusion; 14: skeletal II, mean angle, lingually inclined incisors; 15: skeletal II, high angle, openbite; 16: skeletal III, mean angle, protruded mandible; 17: skeletal III, high angle, protruded mandible; 18: skeletal III, mean angle, retruded maxilla and protruded mandible; 19: skeletal III, high angle, retruded maxilla and protruded mandible; 20: skeletal III, low angle, retruded maxilla and protruded mandible; 21: skeletal III, high angle, openbite

that are typically encountered in the clinic to determine differences in the effects of different treatment methods applied to the same deformity category. The Student $t$ test was used to compare the effects of the treatments. The level of statistical significance was set at $P<0.05$.

\section{Results}

\section{Cluster analysis}

The data of the 2249 patients were subjected to cluster analysis. After the exclusion of subclasses with sample sizes of less than 5 , there remained a total of 21 subclasses. An average diagram of the craniofacial structures of each subclass was drawn based on the computed average coordinates. All 21 CMTs are shown in Fig. 2, and exhibit the mean structures of all the typical subclasses of dentofacial deformities. The initial analysis identified that the clusters (subclasses) could be described in terms of conventional cephalometric measurements. The distribution of the samples among the 21 CMTs is shown in Table 2. Table 3 is a summary table of CMT features.

\section{Discriminant analysis}

The discriminant accuracy of the total sample was $89.1 \%$, while the cross-validation accuracy was $85.0 \%$, indicating that the clusters were robust. This suggested that the CMTs represented the characteristics of most of the subjects in our research. We entered a total of 34 variables into the discriminant equations (Table S1), and 21 discriminant equations were formed (see supplemental files).

Treatment evaluation of three clinically typical subclasses We selected three dentofacial deformity subclasses that are typically observed in clinical practice, and evaluated the treatment outcomes for each of these subclasses. Because the patients in each subclass had received different treatments, we could determine the average changes in a certain subclass after a certain treatment method. The findings of these evaluations can be used not only to assess treatment methods but also to predict treatment outcomes.

Example 1: CMT_5 represented the average features of patients with skeletal, class I, high angle, bimaxillary protrusion. Figure 3 shows the average changes in patients in the CMT_5 group before and after orthodontic treatment (Fig. 3a, b) as well as the morphology diagrams after treatment with (Fig. 3c, d) or without (Fig. 3e, $\mathrm{f}$ ) extraction of the first premolars. The treatment results in this subclass were as follows: (1) In first premolar extraction group, the forward inclination and protrusion of both the upper and lower incisors decreased significantly, and the soft tissues, upper and lower lips, and profile improved significantly. (2) In the group treated without extraction of the first premolars, there were no significant improvements in the inclination of the incisors, protrusion of the lips and the

Table 2 The distribution of the number of patients in the 21 CMTs

\begin{tabular}{|c|c|c|c|c|c|}
\hline CMT type & sample & Percentage(\%) & Male & Female & Mean age \\
\hline CMT_1 & 190 & 8.5 & 48 & 142 & 14.4 \\
\hline CMT_2 & 132 & 5.9 & 41 & 91 & 13.9 \\
\hline CMT_3 & 53 & 2.4 & 18 & 35 & 16.5 \\
\hline CMT_4 & 249 & 11.1 & 93 & 156 & 13.7 \\
\hline CMT_5 & 178 & 7.9 & 60 & 118 & 13.6 \\
\hline CMT_6 & 80 & 3.6 & 21 & 59 & 14.5 \\
\hline CMT_7 & 97 & 4.3 & 26 & 71 & 14.5 \\
\hline CMT_8 & 68 & 3.0 & 6 & 62 & 13.9 \\
\hline CMT_9 & 155 & 6.9 & 64 & 91 & 12.9 \\
\hline CMT_10 & 102 & 4.5 & 39 & 69 & 14.0 \\
\hline CMT_11 & 44 & 2.0 & 24 & 20 & 14.4 \\
\hline CMT_12 & 251 & 11.2 & 72 & 179 & 14.2 \\
\hline CMT_13 & 183 & 8.2 & 61 & 122 & 14.6 \\
\hline CMT_14 & 18 & .8 & 4 & 10 & 16.3 \\
\hline CMT_15 & 78 & 3.5 & 18 & 60 & 17.8 \\
\hline CMT_16 & 140 & 6.2 & 48 & 92 & 14.2 \\
\hline CMT_17 & 68 & 3.0 & 33 & 35 & 11.9 \\
\hline CMT_18 & 67 & 3.0 & 32 & 35 & 14.0 \\
\hline CMT_19 & 25 & 1.1 & 13 & 12 & 20.2 \\
\hline CMT_20 & 26 & 1.2 & 16 & 20 & 17.8 \\
\hline CMT_21 & 34 & 1.5 & 17 & 17 & 17.7 \\
\hline Unclassed & 11 & .5 & 4 & 7 & 13.2 \\
\hline Total & 2249 & 100.0 & 758 & 1491 & 14.3 \\
\hline
\end{tabular}


Table 3 A summary table of template features

\begin{tabular}{|c|c|c|c|}
\hline Template & Criterion & Template & Criterion \\
\hline CMT_1 & $\begin{array}{l}\text { Skeletal Class I } \\
\text { Average angle } \\
\text { Li-E line and Ls-E line are less than } 1 \mathrm{~mm} \text {, or the } \\
\text { sum of the two is less than } 2 \mathrm{~mm}\end{array}$ & CMT_12 & $\begin{array}{l}\text { Skeletal Class II } \\
\text { Average and low angle } \\
\text { Li-E line and Ls-E line are greater than } 2.5 \mathrm{~mm} \text {, or the sum of the two is } \\
\text { equal or greater than } 4 \mathrm{~mm} \\
\text { Overjet is less than } 8 \mathrm{~mm}\end{array}$ \\
\hline CMT_2 & $\begin{array}{l}\text { Skeletal Class I } \\
\text { High angle } \\
\text {-Li-E line and Ls-E line are less than } 1 \mathrm{~mm} \text {, or the } \\
\text { sum of the two is less than } 2 \mathrm{~mm}\end{array}$ & CMT_13 & $\begin{array}{l}\text { Skeletal Class II } \\
\text { High angle } \\
\text { Li-E line and Ls-E line are greater than } 2.5 \mathrm{~mm} \text {, or the sum of the two is } \\
\text { equal or greater than } 4 \mathrm{~mm} \\
\text { Overjet is less than } 8 \mathrm{~mm}\end{array}$ \\
\hline CMT_3 & $\begin{array}{l}\text { Skeletal Class I } \\
\text { Low angle } \\
\text { Li-E line and Ls-E line are less than } 1 \mathrm{~mm} \text {, or the } \\
\text { sum of the two is less than } 2 \mathrm{~mm}\end{array}$ & CMT_14 & $\begin{array}{l}\text { Skeletal Class II } \\
\text { Average and low angle } \\
\text { Upper incisors linguoclination }\end{array}$ \\
\hline CMT_4 & $\begin{array}{l}\text { Skeletal Class I } \\
\text { Average and low angle } \\
\text {-Li-E line and Ls-E line are greater than } 1 \mathrm{~mm} \text {, or } \\
\text { the sum of the two is greater than } 2 \mathrm{~mm}\end{array}$ & CMT_15 & $\begin{array}{l}\text { Skeletal Class II } \\
\text { High angle } \\
\text { Open-bite }\end{array}$ \\
\hline CMT_5 & $\begin{array}{l}\text { Skeletal Class I } \\
\text { High angle } \\
\text {-Li-E line and Ls-E line are greater than } 1 \mathrm{~mm} \text {, or } \\
\text { the sum of the two is greater than } 2 \mathrm{~mm}\end{array}$ & CMT_16 & $\begin{array}{l}\text { Skeletal Class III } \\
\text { Average and low angle } \\
\text { Overjet is less than } 0 \mathrm{~mm} \text { and greater than }-3 \mathrm{~mm} \text { (if the case is low angle, } \\
\text { the range of overjet is less than } 0 \mathrm{~mm} \text { and greater than }-2 \mathrm{~mm} \text { ) }\end{array}$ \\
\hline CMT_6 & $\begin{array}{l}\text { Skeletal Class I } \\
\text { Deep overjet (overjet is equal or greater than } 8 \\
\mathrm{~mm} \text { ) }\end{array}$ & CMT_17 & $\begin{array}{l}\text { Skeletal Class III } \\
\text { High angle } \\
\text { Overjet is less than } 0 \mathrm{~mm} \text { and greater than }-3 \mathrm{~mm}\end{array}$ \\
\hline CMT_7 & $\begin{array}{l}\text { Skeletal Class II } \\
\text {-Average and low angle } \\
\text {-Li-E line and Ls-E line are less than } 2.5 \mathrm{~mm} \text {, or } \\
\text { the sum of the two is less than } 4 \mathrm{~mm}\end{array}$ & CMT_18 & $\begin{array}{l}\text { Skeletal Class III } \\
\text { Average angle } \\
\text { Overjet is less than }-3 \mathrm{~mm}\end{array}$ \\
\hline CMT_8 & $\begin{array}{l}\text {-Skeletal Class II } \\
\text { High angle } \\
\text {-Li-E line and Ls-E line are less than } 2.5 \mathrm{~mm} \text {, or } \\
\text { the sum of the two is less than } 4 \mathrm{~mm}\end{array}$ & CMT_19 & $\begin{array}{l}\text { Skeletal Class III } \\
\text { High angle } \\
\text { Overjet is less than }-3 \mathrm{~mm}\end{array}$ \\
\hline CMT_9 & $\begin{array}{l}\text { Skeletal Class II } \\
\text {-Average angle } \\
\text {-Deep overjet (overjet is equal or greater than } 8 \\
\mathrm{~mm} \text { ) }\end{array}$ & CMT_20 & $\begin{array}{l}\text { Skeletal Class III } \\
\text { Low angle } \\
\text { Overjet is less than }-2 \mathrm{~mm}\end{array}$ \\
\hline CMT_10 & $\begin{array}{l}\text { Skeletal Class II } \\
\text {.High angle } \\
\text {-Deep overjet (overjet is equal or greater than } 8 \\
\mathrm{~mm} \text { ) }\end{array}$ & CMT_21 & $\begin{array}{l}\text { Skeletal Class III } \\
\text {.High angle } \\
\text { Open-bitea }\end{array}$ \\
\hline CMT_11 & $\begin{array}{l}\text { Skeletal Class II } \\
\text {-Low angle } \\
\text {-Deep overjet (overjet is equal or greater than } 8 \\
\mathrm{~mm} \text { ) }\end{array}$ & & \\
\hline
\end{tabular}

profile after treatment. (3) Thus, in patients with craniofacial features of skeletal, class I, high-angle, bimaxillary protrusion, the extraction method is a better alternative that results in better treatment efficacy.

Example 2: CMT_18 represented the average features of patients with skeletal, class III, average angle, maxillary retrusion, and mandibular protrusion. Figure 4 shows the average changes in patients in the CMT_18 group before and after orthodontic treatment (Fig. 4a, b) as well as the morphology diagrams after treatment with the Frankel III appliance (F-III; Fig. 4c, d) or with anterior protraction
(Fig. 4e, f) without extraction. The treatment results in this subclass were as follows: (1) There were significant changes in the jaw relationships in both groups, but the changes were more obvious in the anterior protraction group. (2) The mandibular plane angle increased and the profile obviously improved in both groups. (3) In patients with craniofacial features of skeletal, class III, average angle, maxillary retrusion, and mandibular protrusion, the F-III functional appliance and anterior protraction were both effective. (4) Compared with the F-III functional appliance, anterior protraction had greater efficacy, which is consistent with previous studies. 


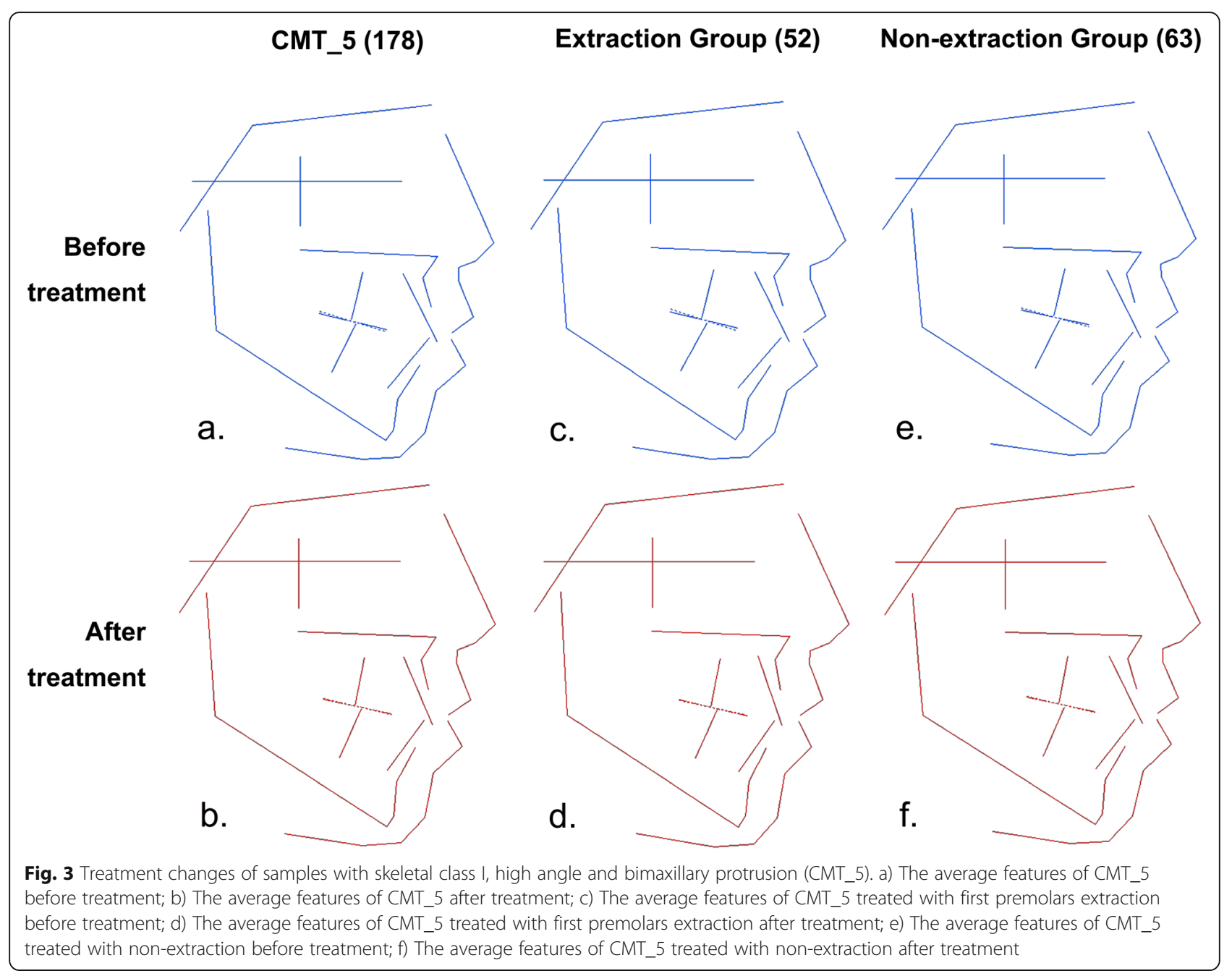

Example 3: CMT_19 represented the average features of patients with skeletal, class III, high angle, maxillary retrusion, and mandibular protrusion. Figure 5 shows the average changes in patients in the CMT_19 group before and after treatment (Fig. 5a, b) as well as the morphology diagrams after non-surgical treatment (Fig. 5c, d) or after orthognathic surgery (Fig. 5e, f). The results were as follows: (1) Orthognathic surgery could improve jaw relationships and coordinate the hard and soft tissues more effectively. (2) Non-surgical treatment could change certain craniofacial features to a limited extent, but with less obvious effects than orthognathic surgery.

\section{Discussion}

The main purpose of this study was to form biologically informative, digital templates of dentofacial deformities, so as to enable rapid, computerized, automatic diagnoses by matching the imaging data of a new patient with the characteristic templates. A comprehensive and accurate classification is critical to the process of template establishment. Subclasses of dentofacial deformities have been described in the literature [20, 23, 25]. However, most such classification systems rely on a single angle measurement or molar relationship. A comprehensive classification of deformity patterns requires subclasses that are not based on a single variable alone. Moyers et al. classified 697 patients with class II malocclusions into six horizontal and five vertical divisions by using cluster analysis, and developed diagnostic definitions and designed treatment plans pertaining to each subclass [20].

In this study, we used cluster analyses with no a priori definitions to establish a classification system of craniofacial deformities. This research was carefully designed to avoid the shortcomings that were limited by sample size or selection bias. We included a sample of 2249 patients with any type of malocclusion and performed a comprehensive analysis of as many cephalometric landmarks as possible. Considering the ethnic diversity, we only recruited Han population into the sample. The cephalometric measurements were obtained by working 


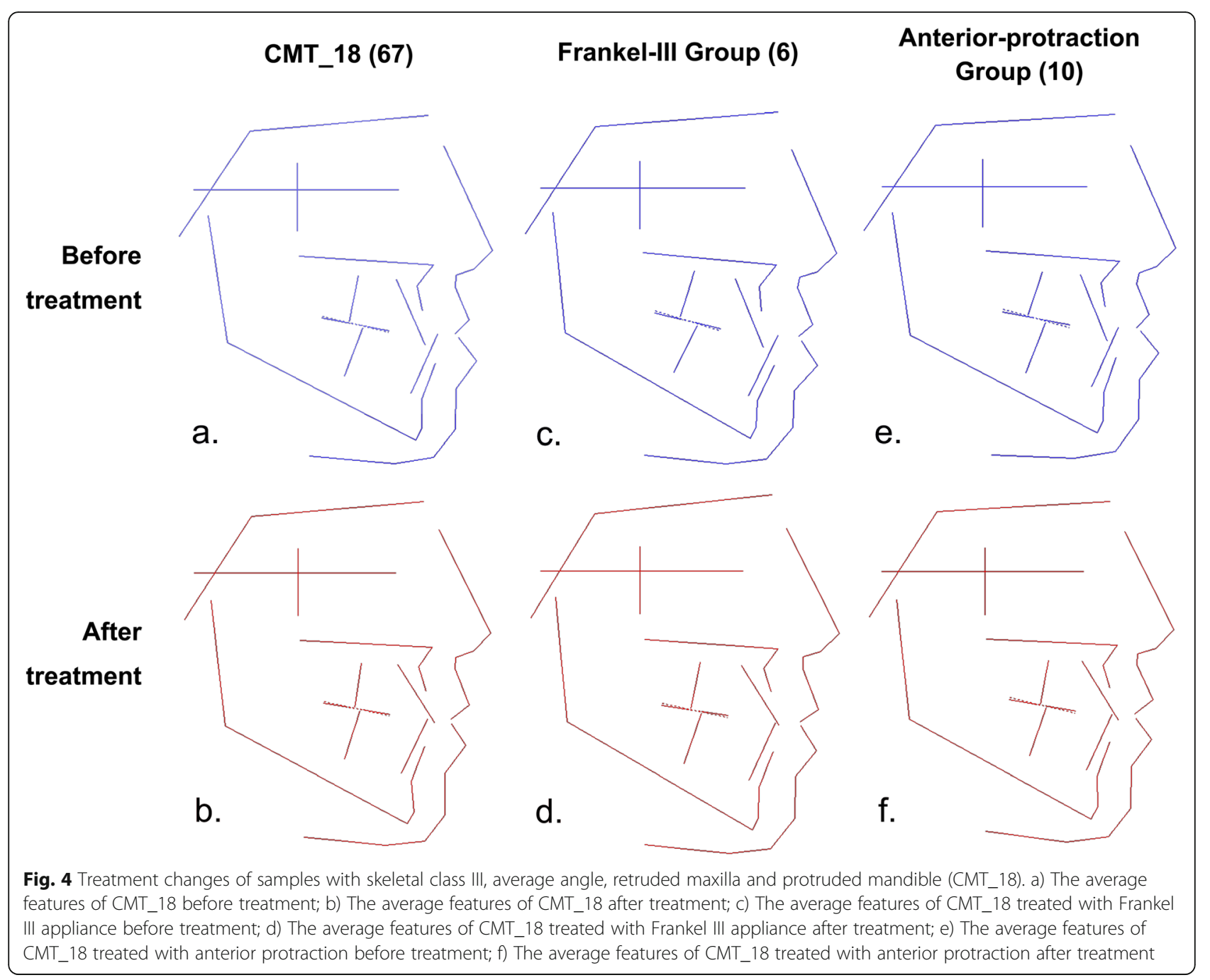

out the average locations of the selected landmarks. All the landmarks were independently identified and located by three professionally trained orthodontic residents. The data were calibrated, which helped to ensure the accuracy of the results. A total of 21 CMTs were established representing almost all patterns of dentofacial deformities. These cephalometric values and CMTs could not completely represent of an ethnicity, but can still be used for reference.

The most commonly used method to evaluate therapeutic effects in previous studies was choosing one type of malocclusion (mostly based on Angle's classification), and then statistically analyzing cephalometric measurements before and after treatment. This method is simple, appropriate to understand and widely used. However, there are two obvious flaws in this method. First, the classification of the entire sample is based on a single feature, such as molar relationships or jaw relationships, ignoring the influences of other confounding features. Second, line and angle measurements cannot reflect the overall dentofacial morphology, unlike the main landmarks shown on CMTs (Fig. 1). The CMTs formed from this cluster analysis are based on landmark information, and therefore, the resultant classification based on these CMTs will ensure a high degree of sample similarity within the same subclass. The CMT of a large sample represents the mean morphology of a pattern of similar structures, and the changes in the CMT before and after treatment represent the mean morphological changes in samples with similar structures. This close similarity will greatly increase the reliability of efficacy analysis. CMTs contains much more cranial and maxillofacial deformities than traditional method.

Another obvious advantage of CMTs is that they can be calculated on the computer and display the changes in the position of landmarks. Therefore, the changes before and after treatment can be seen intuitively, which is more conducive to orthodontists' judgment and doctorpatient communication. Although hand-traced templates have been used to evaluate the dentofacial characteristics 


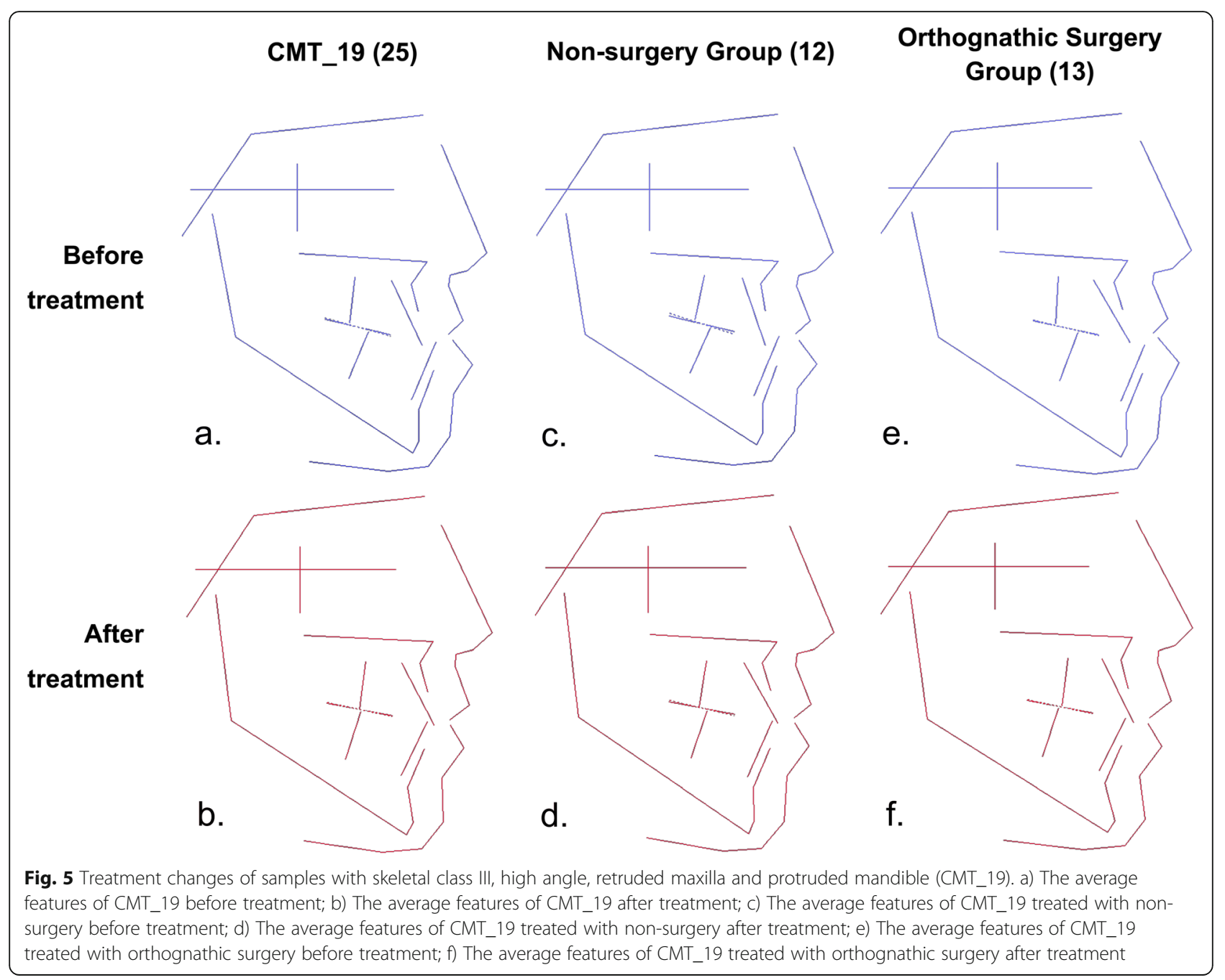

of patients [5, 6], predict growth [7] and perform diagnoses [8], few such templates have been used for treatment evaluation. CMT analysis is akin to traditional superimposition analysis, but is more effective than superimposition and better reflects average changes for a class of samples.

For example, we subdivided patients in the CMT_5 subclass, which is a common type in clinical practice, into two groups based on whether or not they underwent tooth extraction. Great improvement in the profile was seen in the extraction group, with significant reductions in the inclination of the upper and lower incisors and in lip protrusion (Fig. 3). In contrast, the soft and hard tissues were not well improved in the nonextraction group, and protrusive incisors and a convex profile persisted after treatment.

The clinical effects of functional appliances are controversial, whereas anterior protraction treatment for skeletal, class III malocclusion is commonly viewed as being efficient [26]. We therefore compared the efficacy of the
F-III appliance and anterior protraction in the patients in the CMT_18 subclass, which pertained to skeletal, class III malocclusions (Fig. 4). We found that the ANB angle was more significantly improved in the anterior protraction group than in the F-III functional appliance group, which is consistent with previous studies. Anterior protraction seemed to be more beneficial for skeletal improvement, whereas the F-III appliance seemed to better improve soft tissues. The profile improved well in both groups, without obvious differences. The results seemed to suggest that both methods could be used to treat patients with skeletal, class III malocclusions in mixed dentition or early permanent dentition.

Since the computer system is not yet operational and needs further improvement, there are two main ways to use templates today. First, these templates are a morphological template based on coordinate clustering. Morphological matching could be used quickly in the clinic for reference by these templates, but it is not the most accurate way to use. Second, to get an accurate result, a 
computer is needed to substitute the coordinate value into the equation. Substitute the coordinate values of the sample into the 21 discriminant equations to see which equation results in a higher value. The sample corresponds to the group with the largest result value of the discriminant equation.

However, the best way to do this is to automate it all. Therefore, the goal in the future is to use software to achieve accurate discrimination. Although we only partially contrasted the effects of several treatment methods in a relatively large number of samples, this is exploratory investigation can provide a basis for future research into the prediction of treatment outcomes in patients with dentofacial deformities. New cases will be gradually accumulated in the informative CMT database, which will be enriched with information about the outcomes of different treatment methods.

In addition to treatment evaluation, this study is superior in many aspects, including the large sample size, cross-validation, and general diversity. Most importantly, a priori definitions were not applied before clustering. In this study, all 2249 patients without a priori pattern definitions were divided by cluster analysis based on the coordinates of their lateral cephalograms rather than the conventional Angle's classification. In this way, samples of each subclass had integral dentofacial similarity, and represented almost all types of dentofacial deformities.

\section{Conclusion}

This study demonstrates the utility of clustering methods for grouping dentofacial deformities with similar features in the age of big data. We established 21 biologically informative templates of different dentofacial deformities. Our study will provide references for rapid template matching and thereby enable the fast, computerized diagnosis of dentofacial deformities. In addition, comparative research on treatment efficacies in samples with highly similar dentofacial morphologies based on the CMTs will be more objective. The CMTs formed in this study will enable rapid diagnoses, the designing of treatment plans based on the evaluation of the treatment outcomes of samples affiliated with the same CMT, and the prediction of treatment outcomes. The findings of this study are necessary to develop novel, biological data-driven methods for dentofacial diagnosis and treatment outcome prediction. The CMTs described in this study are expected to enable the critical transition to computerized, fully automatic, pinpoint measurements in the near future.

\section{Supplementary Information}

The online version contains supplementary material available at https://doi. org/10.1186/s13005-022-00309-2.
Additional file 1: Table S1. There are 34 coordinates of the landmarks entering into the discriminant equations. Each of them are represented as variables $\mathrm{Xn}$ in the equations.

\section{Acknowledgements}

We appreciate Dr. Sa Li and Dr. Bin Na for their assistance during the preparation of the manuscript. We gratefully thank the staff of the Department theof Oral and Maxillofacial Radiology for their assistance.

\section{Authors' contributions}

Conceptualization, H.S.; methodology, WH.L.; validation, B.H., Y.W. and TM.X.; formal analysis, H.S. and WH.L.; investigation, JJ.D and G.C.; data curation, RP.J. and XY.Z; writing-original draft preparation, H.S., WH.L; writing-review and editing B.H., Y.W. and TM.X.; supervision, B.H.; project administration, B.H. and TM.X. All authors have read and agreed to the published version of the manuscript.

\section{Funding}

This work was supported by the National Key R\&D Program of China, grant number 2020YFA0710401; the National Natural Science Foundation of China, grant number 51972005, 82071172, 82001080, 51672009; the Program for New Clinical Techniques and Therapies of Peking University School and Hospital of Stomatology (PKUSSNCT-19A05); the National Natural Science Foundation of China Youth Fund, grant number 81922019, and the National Youth Top-notch Talent Support Program, grant number QNBJ2019-3.

\section{Availability of data and materials}

The datasets used and/or analyzed during the current study are available from the corresponding author on reasonable request.

\section{Declarations}

\section{Ethics approval and consent to participate}

The study protocol was approved by the ethics committee of Peking University School of Stomatology (PKUSSIRB-201626016), got approval to dispense with informed consent, and adhered to the tenets of the Declaration of Helsinki. Due to the retrospective design of this study, consent to participate was not mandatory.

\section{Consent for publication}

All authors gave written consent for publication in the Head\&Face Journal. All participant of the current study gave their written informed consent to the Study.

\section{Competing interests}

All authors declare that they have no competing interests.

\section{Author details}

${ }^{1}$ Department of Orthodontics, Cranial-Facial Growth and Development Center, Peking University School and Hospital of Stomatology, 22 Zhongguancun South Avenue, Haidian District, Beijing 100081, People's Republic of China. ${ }^{2}$ First Clinical Division, Peking University School and Hospital of Stomatology, 37A Xishiku Street, Xicheng District, Beijing 100034 People's Republic of China. ${ }^{3}$ National Center of Stomatology \& National Clinical Research Center for Oral Diseases \& National Engineering Research Center of Oral Biomaterials and Digital Medical Devices \& Research Center of Engineering and Technology for Computerized Dentistry Ministry of Health \& NMPA Key Laboratory for Dental Materials, 22 Zhongguancun South Avenue, Haidian District, Beijing 100081, People's Republic of China. ${ }^{4}$ Department of Geriatric Dentistry, Peking University School and Hospital of Stomatology, 22 Zhongguancun South Avenue, Haidian District, Beijing 100081, People's Republic of China.

Received: 4 September 2021 Accepted: 31 January 2022 Published online: 14 February 2022

\section{References}

1. Broadbent $\mathrm{BH}$. A new $\mathrm{x}$-ray technique and its application to orthodontia. Angle Orthodontist. 1931;1(2):45-66. 
2. Walker SJ, Harris JE, Kowalski CJ. SNA and SNB angles in a population of Nubian schoolchildren. J Dent Res. 1975;54(4):764-6. https://doi.org/10.1177/ 00220345750540041101

3. Walker GF, Kowalski CJ. Use of angular measurements in cephalometric analyses. J Dent Res. 1972;51(4):1015-21. https://doi.org/10.1177/0022034 5720510040401.

4. Björk A, Solow B. Measurement on radiographs. J Dent Res. 1962;41(3):67283. https://doi.org/10.1177/00220345620410032101.

5. Harris JE, Johnston L, Moyers RE. A cephalometric template: its construction and clinical significance. Am J Orthod. 1963;49(4):249-63. https://doi.org/1 0.1016/0002-9416(63)90002-2

6. Johnston LE Jr. Template analysis. J Clin Orthod JCO. 1987;21(9):585-90.

7. Popovich F, Thompson GW. Craniofacial templates for orthodontic case analysis. Am J Orthod. 1977;71(4):406-20. https://doi.org/10.1016/0002-941 6(77)90244-5.

8. Hans MG, Broadbent BH Jr, Nelson SS. The Broadbent-Bolton Growth Study--past, present, and future. Am J Orthod Dentofac Orthop. 1994;105(6): 598-603. https://doi.org/10.1016/S0889-5406(94)70145-8.

9. Lowe BF Jr, Phillips C, Lestrel PE, Fields HW Jr. Skeletal jaw relationships: a quantitative assessment using elliptical Fourier functions. Angle Orthod. 1994;64(4):299-308. https://doi.org/10.1043/0003-3219(1994)064<0299:SJRA QA>2.0.CO;2.

10. Kim JY, Lee SJ, Kim TW, Nahm DS, Chang YI. Classification of the skeletal variation in normal occlusion. Angle Orthod. 2005;75(3):311-9. https://doi. org/10.1043/0003-3219(2005)75[311:COTSVI]2.0.CO;2.

11. Abu Alhaija ESJ, Richardson A. Growth prediction in class III patients using cluster and discriminant function analysis. Eur J Orthodont. 2003;25(6):599608. https://doi.org/10.1093/ejo/25.6.599.

12. Chang HP, Liu PH, Yang YH, Lin HC, Chang CH. Craniofacial morphometric analysis of mandibular prognathism. J Oral Rehabil. 2006;33(3):183-93. https://doi.org/10.1111/j.1365-2842.2005.01563.x.

13. Hennessy RJ, Moss JP. Facial growth: separating shape from size. Eur J Orthod. 2001;23(3):275-85. https://doi.org/10.1093/ejo/23.3.275.

14. O'Grady KF, Antonyshyn OM. Facial asymmetry: three-dimensional analysis using laser surface scanning. Plast Reconstr Surg. 1999;104(4):928-37. https://doi.org/10.1097/00006534-199909040-00006.

15. Sameshima GT, Melnick M. Finite element-based cephalometric analysis. Angle Orthod. 1994;64(5):343-50

16. Hu CYW, Kornblau SM, Slater JH, Qutub AA. Progeny clustering: a method to identify biological phenotypes. Sci Rep-Uk. 2015;5(1). https://doi.org/10.1 038/srep12894.

17. Chang HP, Lin HC, Liu PH, Chang CH. Geometric morphometric assessment of treatment effects of maxillary protraction combined with chin cup appliance on the maxillofacial complex. J Oral Rehabil. 2005;32(10):720-8. https://doi.org/10.1111/j.1365-2842.2005.01504.x.

18. Palone M, Spedicato GA, Lombardo L. Analysis of tooth anatomy in adults with ideal occlusion: A preliminary study. Am J Orthod Dentofac. 2020: 157(2).

19. Shaffer JR, Feingold E, Wang X, Lee M, Tcuenco K, Weeks DE, et al. GWAS of dental caries patterns in the permanent dentition. J Dent Res. 2013;92(1): 38-44. https://doi.org/10.1177/0022034512463579.

20. Moyers RE, Riolo ML, Guire KE, Wainright RL, Bookstein FL. Differential diagnosis of class II malocclusions. Part 1. Facial types associated with class II malocclusions. Am J Orthod. 1980;78(5):477-94. https://doi.org/10.1016/ 0002-9416(80)90299-7.

21. Shaffer JR, Feingold E, Wang X, Weeks DE, Weyant RJ, Crout R, et al. Clustering tooth surfaces into biologically informative caries outcomes. J Dent Res. 2013;92(1):32-7. https://doi.org/10.1177/0022 034512463241

22. Psoter WJ, Pendrys DG, Morse DE, Zhang HP, Mayne ST. Caries patterns in the primary dentition: cluster analysis of a sample of 5,169 Arizona children 5-59 months of age. Int J Oral Sci. 2009;1(4):189-95. https://doi.org/10.4248/ IJOS09077.

23. Finkelstein M, Lavelle CLB, Hassard T. The role of cluster-analysis on traditional cephalometric dimensions. Angle Orthod. 1989;59(2):97-106.

24. Baumrind S, Frantz RC. The reliability of head film measurements: 1 . Landmark identification. Am J Orthod. 1971;60(2):111-27. https://doi.org/1 0.1016/0002-9416(71)90028-5.

25. Hong SX, Yi CK. A classification and characterization of skeletal class III malocclusion on etio-pathogenic basis. Int J Oral Maxillofac Surg. 2001;30(4): 264-71. https://doi.org/10.1054/ijom.2001.0088.
26. Kapust AJ, Sinclair PM, Turley PK. Cephalometric effects of face mask/ expansion therapy in class III children: a comparison of three age groups. Am J Orthod Dentofac Orthop. 1998;113(2):204-12. https://doi.org/10.1016/ S0889-5406(98)70141-6.

\section{Publisher's Note}

Springer Nature remains neutral with regard to jurisdictional claims in published maps and institutional affiliations.
Ready to submit your research? Choose BMC and benefit from:

- fast, convenient online submission

- thorough peer review by experienced researchers in your field

- rapid publication on acceptance

- support for research data, including large and complex data types

- gold Open Access which fosters wider collaboration and increased citations

- maximum visibility for your research: over $100 \mathrm{M}$ website views per year

At $\mathrm{BMC}$, research is always in progress.

Learn more biomedcentral.com/submissions 